\title{
Carbon sink forest in Expressway under the guidance of low carbon transportation
}

\author{
Chaocheng Zheng ${ }^{1,2}$ Yi Zhang ${ }^{1,2}$ and Dongxiang Cheng ${ }^{1,2}$ \\ ${ }^{1}$ Nanjing Communications Institute of Technology, Nanjing 211188, China; \\ 2 Jiangsu Engineering Technology Research Center for Energy Conservation and Emission \\ Reduction of Transportation, Nanjing 211188, China.
}

Keywords: Expressway, interchange area, carbon sink, low carbon traffic environment

\begin{abstract}
Carbon sink concept was introduced based on principles of green design, construction in expressway. In the design and construction process, in addition to take basic requirements such as function and beauty into consideration, carbon sink will be added to create a low carbon traffic environment.
\end{abstract}

\section{Introduction}

With the development of national economy, the quantity of motor vehicles in China has maintained a rapid growth. Till to March of year 2013, the national motor vehicle fleet is 1.92 million, with total mileage of up to 65 thousand kilometers of expressway in correspondence.

According to statistics, gases released from cars, ship aircraft and other transportation tools are one of the main reasons for global warming. In the past ten years, CO2 emissions were increased by $13 \%$, while growth rate of carbon emissions from vehicles is up to $25 \%$. It is estimated that in the next 25 years, CO2 in global traffic sources will be increased by $57 \%$, hence, to build carbon sink forest along the highway is our responsibility to create a low carbon traffic environment.

\section{Necessity to develop low carbon traffic}

Developing a low-carbon economy has become inevitable for China in coping with climate change. As a responsible developing country, China has internalized low-carbon economy into its overall development strategy and is making unremitting efforts to realize objectives of temperature control and sustainable development. At the end of 2009, the Central Economic Work Conference, which put forward climate change and greenhouse gas emissions control objectives, demonstrated that the Chinese now have clearer ideas of how to proceed along the road toward a low-carbon economy[1].

In China's energy production and consumption composition, coal accounts for approximately 70 percent, mainly in electric power generation. The concern is: How will China manage to cut carbon emissions given its present stage of industrialization?

"Since it adopted its policy of reform and opening up, China has always been committed to working on coal fired generation efficiency and purification levels" - this is not the judgment of a single person but a statement in the Policy on Sustainability of Coal and Pollution Control issued by the China Council for International Cooperation on Environment and Development in 2009.

Statistics support this assertion: By the end of 2008, China's electric power installed capacity had reached 792 million $\mathrm{kw}$, of which 600 million kw came from coal power. In the area of coal power, large-scale units with a capacity of more than 300,000 kw already accounted for more than 50 percent. China also raised average efficiency in thermal power. By 2008, the amount of coal necessary to produce each $\mathrm{kw} / \mathrm{h}$ of electric power had dropped to 349 grams of standard coal, lower than the United States and Germany in 2005.

Its coal-centered energy production together with accelerated industrialization and urbanization have made it impossible for China to realize low-carbon coal consumption practices overnight. It has not been easy for China to reach the level it is at today. 
While increasing coal efficiency and purification levels, China is also making great efforts to develop clean power from sources such as wind, the sun, hydropower, nuclear power and biomass energy. By the end of 2008, clean energy made up 9 percent of China's primary energy consumption. Its hydropower installed capacity, the scale of current nuclear power development, heating generated through colar power and its accumulated capacity of solar energy photovoltaic power generation ranked the world's first while the installed capacity of wind power ranked the world's fourth.

\section{Forest carbon sinks work}

China's leaders repeatedly mention planning to increase forest carbon sinks. By 2020, China's forest coverage will have increased by 40 million hectares compared to 2005 and forest volume increased by 1.3 billion cubic meters from 2005.

Experts believe that to cope with climate change, we need to "walk two paths." One is emissions reductions in industry, construction and traffic, and the other is forest carbon sinks. A forest carbon sink refers to the process of forests absorbing carbon dioxide from the atmosphere and storing it in plants or the earth, so as to reduce its density in the air. Compared with direct emissions reductions in industry, forest carbon sinks are a kind of indirect emissions reduction. They make little demand in investment and costs, but provide comprehensive benefits. Therefore, it's quite a practical and economical way to reduce emissions. Every hectare of forest is able to absorb between 20 and 40 tons of carbon dioxide[2].

In November 2009, China's State Council announced the $7^{\text {th }}$ general forest inventory, which showed China's national forest coverage had reached more than 1.95 trillion hectares and the country's forest coverage rate jumped to 20.36 percent. At the 2007 APEC conference, China made a commitment to the world to increase forest coverage rate to 20 percent by 2010, which was realized well ahead of time.

It's worth mentioning that the interval between this forest inventory and the previous one was five years. During this period, the net growth of China's forest coverage was more than 20.54 million hectares, forest stock increased by more than 1.12 billion cubic meters and the national coverage reached 20.36 percent from 18.21 percent. A 2.15 percent growth seems like nothing, but given huge annual demand for timber, unavoidable felling in the forests and a relatively low survival rate of new planting, the growth was a big plus. During the 25 years from 1980 and 2005, thanks to the continuous efforts of tree planting, forest operations and control over felling, some 5.11 billion tons of carbon dioxide were absorbed or otherwise reduced.

\section{Construction of carbon sink forest in highway interchange area}

Carbon dioxide (CO2) is one of the nutrients essential to building the organic chemicals that comprise leaves, roots, and stems. All parts of a plant - the stem, limbs and leaves, and roots contain carbon, but the proportion in each part varies enormously, depending on the plant species and the individual specimen' s age and growth pattern. Nonetheless, as more photosynthesis occurs, more CO2 is converted into biomass, reducing carbon in the atmosphere and sequestering (storing) it in plant tissue (vegetation) above and below ground.

Forests generally go through cycles of growth and death, sequestering and releasing carbon. Some forests begin on spacious sites, with little or no existing vegetation, that may have been cleared by a natural disaster (most commonly wildfire) or by human activities (e.g., for agriculture). Other forests are relatively continuous, with natural clearings typically limited to the area occupied by one or a few large trees killed by lightning, disease, and such. Regardless of the size or origin of a clearing, most forests begin from essentially bare land, with some carbon stored in the soil (how much depends on the environment and history of the site, especially the last clearing process).

As trees and other woody plants become established, carbon stored on the site increases as woody biomass increases and as annual vegetation (e.g., tree leaves and herbaceous plants) typically grows faster than it decomposes. Productivity for commercially usable wood generally follows an S-shaped 
curve, with the volume growing at an increasing rate for many years, to a point known to foresters as the culmination of mean annual increment (generally taking 20 to 100 years or more, depending on the fertility of the site and the tree species), and then growing at a decreasing rate for many more years. In theory, forests can eventually become "over-mature," where the loss of commercial volume through tree mortality equals or exceeds the additional growth on the remaining trees. However, one study has shown that some old-growth ("over-mature") forests continue to accumulate carbon in their soils[3].

The relationship between commercially usable wood produced and carbon sequestered varies substantially in three ways. First, the proportion of carbon in a tree' s commercial wood (compared to the noncommercial biomass in bark, limbs, roots, and leaves or needles) varies among species; some (e.g., pines and other conifers) have a greater proportion of their total carbon in commercial wood. Second, the proportion of carbon in a tree's commercial wood undoubtedly changes over time; while a temporal graph of carbon storage is probably also Sshaped (as for commercial wood productivity), the changes in timing and rates of increase (that cause the characteristic $S$ shape) almost certainly differ. Finally, a significant portion of the vegetative carbon sequestered in a forest is in other plants - noncommercial species of trees, shrubs, grasses, and other herbaceous plants. The amount of carbon stored in this other (noncommercial) growth varies widely among forests. Thus, although many research studies assume a fixed relationship between commercial wood inventories and the amount of carbon stored,10 the traditional measures of commercial wood production might not be very accurate for estimating carbon sequestration in forests.

Eventually, trees die. They may be cut down, burned in a wildfire, blown over or snapped off in a wind or ice storm, or killed by insects or diseases. Death can happen to a single tree in a forest, creating a small opening, or to all or most trees in an area. How quickly the carbon is released to the atmosphere depends on the cause of tree death, on whether it is harvested for use, and on various environmental factors. As noted above, fires quickly break down biomass and release an enormous amount of CO2 into the atmosphere. Natural death and decay may require several weeks to several decades to completely decompose the biomass (depending on site conditions), putting some carbon into the soil and some directly into the atmosphere. Timber harvesting can store some vegetative carbon for very long periods in solid wood products with long-term uses (e.g., construction lumber in houses), while tree tops and limbs and noncommercial species are left to decay or to be burned. These possibilities are discussed in more depth below, under "Forestry Events and Management Activities".

Carbon sequestration and release vary substantially by forest. Nonetheless, some generalizations are possible, because of the relative similarity of forests in specific "biomes"-tropical, temperate, and boreal forests. Table 1 shows average carbon levels sequestered in vegetation and soils for several major biomes, and the weighted average for all biomes.

Table 1 Average Carbon Stocks for Various Biomes (in tons per acer)

\begin{tabular}{cccc}
\hline Numble & Pants & Soil & Total \\
\hline Tropical forests & 54 & 55 & 109 \\
Temperate forests & 25 & 43 & 68 \\
Boreal forests & 29 & 153 & 182 \\
Tundra & 3 & 57 & 60 \\
Croplands & 1 & 36 & 37 \\
Tropical savannas & 13 & 52 & 65 \\
Temp. grasslands & 3 & 105 & 108 \\
Desert/semidesert & 1 & 19 & 20 \\
Wetlands & 19 & 287 & 306 \\
Weighted Average & 14 & 59 & 73 \\
\hline
\end{tabular}

Source: Adapted from Intergovernmental Panel on Climate Change, “Table 1: Global carbon stocks in vegetation and carbon pools down to a depth of $1 \mathrm{~m}$ [meter]," Summary for Policymakers: Land Use, Land-Use Change, and Forestry. A Special Report of the Intergovernmental Panel on Climate Change, at http://www.ipcc.ch/pub/srlulucf-e.pdf, p. 4. 
Hence, a carbon sink is a natural or artificial reservoir that accumulates some carbon-containing chemical compound for an indefinite period. The process by which carbon sinks remove carbon dioxide (CO2) from the atmosphere is known as carbon sequestration. Public awareness of the significance of CO2 sinks has grown since passage of the Kyoto Protocol, which promotes their use as a form of carbon offset. There are also different strategies to enhance this process.

Though different countries have various views on how to count carbon sequestered or released from forests. In general, countries with extensive and expanding forests (e.g., Russia, Canada, Brazil, and the United States) prefer a full accounting, while countries with less forestland (e.g., many European countries) are concerned about the potential to overstate the carbon benefits of forestry management practices and land use changes that enhance carbon sequestration. Countries with net deforestation rates are also concerned about counting forest sequestration, because it could effectively increase their net emission rated under international agreements.

According to this idea, samples were detected according to forestry, statistics in ecology theory, using methods such as index test, sample plot monitoring, model simulation, statistical analysis to select high carbon sequestration afforestation tree species, tend carbon measurement and carbon sink monitoring technology to form a carbon sink afforestation and measurement technology guide finally so as to put forward carbon sink balance effect.

\section{Summary}

Forests store substantial amounts of carbon. The amount stored, however, changes over time as forests grow and die. Land use changes and forestry practices alter the level and rates of carbon storage, while "leakage" (shifting production) may offset some of the increases in forest carbon sequestration. Whether and how to account for this carbon sequestration in policies and programs to mitigate climate change has been controversial. Because of the scientific uncertainties, as well as differences in the types and extent of forests among nations, reaching agreement on ways to account for carbon sequestration in forests has been difficult. Some argue for a broadly inclusive accounting, others for a more conservative approach. "Land-based" or "activity-based" models are generally proposed for estimating changes in carbon storage. However, ambiguous language and terminology used by proponents contribute to the inherent difficulties of measuring baseline carbon stocks, land uses, the carbon impacts of various activities, and "leakage” (shifting land or product uses). Furthermore, the enormous diversity of forest types and widespread disputes over the carbon consequences of various practices make it difficult to generalize about the opportunities to mitigate global climate change through forest carbon sequestration. It is likely that research to reduce some of these ambiguities and uncertainties will be an ongoing element in the efforts of nations to deal with carbon sequestration — and with concerns about climate change.

\section{Acknowledgements}

This work was supported by a grant from Transportation Scientific Research Project of Jiangsu Province, Jiangsu Provincial Communications Department (2016Y21) .

\section{References}

[1]. Marland, G., K. Fruit, and R. Sedjo. Accounting for sequestered carbon: The question of performance. Environment Science and Policy . Vol. 4 (2001) No. 11, p. 259-268.

[2]. Van Kooten G.C., C.S. Binkley, G. Delcourt. Effect of carbon taxes and subsidies on optimal forest rotation age and supply of carbon services. American Journal of Agricultural Economics. Vol. 77 (1995) No. 14, p. 365-374.

[3]. Information on: http://www.climatechange.gc.ca. 